\title{
Accuracy of electoral registers and family practitioner committee lists for population studies of the very elderly
}

\author{
ANN BOWLING, ${ }^{1 *}$ DEBBIE HART,${ }^{2}$ AND ALAN SILMAN. ${ }^{2} \dagger$ \\ From the Departments of ${ }^{1}$ Community Medicine, City and Hackney Health Authority and ${ }^{2}$ Clinical Epidemiology, \\ The London Hospital Medical College, London E1, United Kingdom.
}

\begin{abstract}
Study objective: The purpose of the study was to assess the accuracy of Family Practitioner Committee (FPC) lists for identifying very elderly people registered with general practitioners.

Design: The accuracy of available FPC lists was checked against the most recent electoral register to determine which recorded individuals were still living at their FPC registered addresses. This was followed by a postal and home visit enquiry to validate the accuracy of the electoral register.

Setting: The study was carried out in the London borough of Hackney.

Participants: The investigation was confined to persons aged 85 and over.

Results: Of a total of 3018 people listed as being 85 years or over by the FPC, $1183(39 \%)$ were listed on the electoral register. Of these, $751(63 \%)$ were living at their registered address, ie $25 \%$ of the people in the original FPC list. A further $154(5 \%)$ of the original list were not recorded on the electoral register but were alive at the FPC recorded address.

Conclusions: the use of FPC lists alone to identify the very elderly in an inner city population is too inaccurate to be of value. The combined use of FPC lists and the electoral register is better but one in six persons will still be missed.
\end{abstract}

Demographic change within the United Kingdom has resulted in an absolute and relative increase in the numbers of very elderly people (aged 85 years and over) in the population. The policy implications are evident in the light of surveys which report that the proportion of people who suffer from some form of disability which interferes with their daily life increases steeply after the age of 70 for all categories of severity. ${ }^{1}$ The health and other needs of this very elderly group will need to be assessed by population based surveys to determine the appropriate level of service provision required. Two sampling frames are available for undertaking community based studies of the elderly. These are (1) lists of patients registered with NHS general practitioners, either based on the general practitioners' own age-sex registers or the lists held by

\footnotetext{
*Presently Senior lecturer (health services research), Health Services Research Unit, Department of Public Health and Policy, London School of Hygiene and Tropical Medicine, London WC1.
}

tNow Director, Arthritis and Rheumatism Council Epidemiology Research Unit, University of Manchester. the relevant Family Practitioner Committee, and (2) local authority electoral registers. General practitioners' age-sex registers of patients may be the most accurate, but are not kept or maintained by all practitioners, and are not always available to researchers or planners. The advantage of Family Practitioner Committee lists is that they provide date of birth directly, whereas use of the electoral roll requires an additional screening exercise to determine those in the appropriate age range. ${ }^{2}$

Most elderly people eligible to vote are included on the electoral registers. $^{2} 3$ The problem with registrations among the elderly is due to blanks-in practice, failure to return a form from an address results in continuing registration based on the previous year's information. However, electoral registers are updated annually, so accounting for deaths or changes of address should be facilitatedalthough the new addresses of those who have moved will not be traceable. Family Practitioner Committee lists are also frequently inaccurate due to difficulty in enforcing notification of death or change of address. A further very small proportion of elderly people are not registered with a general practitioner. ${ }^{4}$ 
All these problems are likely to be magnified in an inner city area which is characterised by greater population mobility and more single person households. Few studies based on population samples of elderly people taken from general practitioner and Family Practitioner Committee lists have reported on their tracing and response rates. Of those that have, the proportions traced have varied from $78 \%$ from rural Family Practitioner Committee lists ${ }^{5}$ to $82-93 \%$ from lists of rural and urban general practitioners. ${ }^{6-8}$ These figures appear high and might not reflect the situation in a highly mobile inner city area. Thus it was decided to conduct a validation exercise of Family Practitioner Committee lists, using the electoral register and postal enquiries, in a population based study in inner London.

\section{Methods}

The subjects for this study were initially selected from the Family Practitioner Committee lists of patients registered with NHS general practitioners. Patients were eligible for entry into the study if they were aged 85 years and over and listed as living at home in Hackney in October, 1986. A total of 3018 people were identified who fulfilled these criteria. The actual status of these individuals was determined by a fairly complex procedure using the results from two concurrent inquiries of the same population, related to the health of the elderly, and will be described separately. The methods used are shown in fig 1 . In brief, the Family Practitioner Committee list was checked against the then (1986) current electoral register and all those still registered were visited at home or contacted by telephone or letter. The current vital status and address was available for the majority, although for some no response was obtained. Information where available was obtained from neighbours or the current occupant of the registered address. At the end of the interviewing period, the individuals still untraced were checked again on the then current electoral register (1987) and deletions

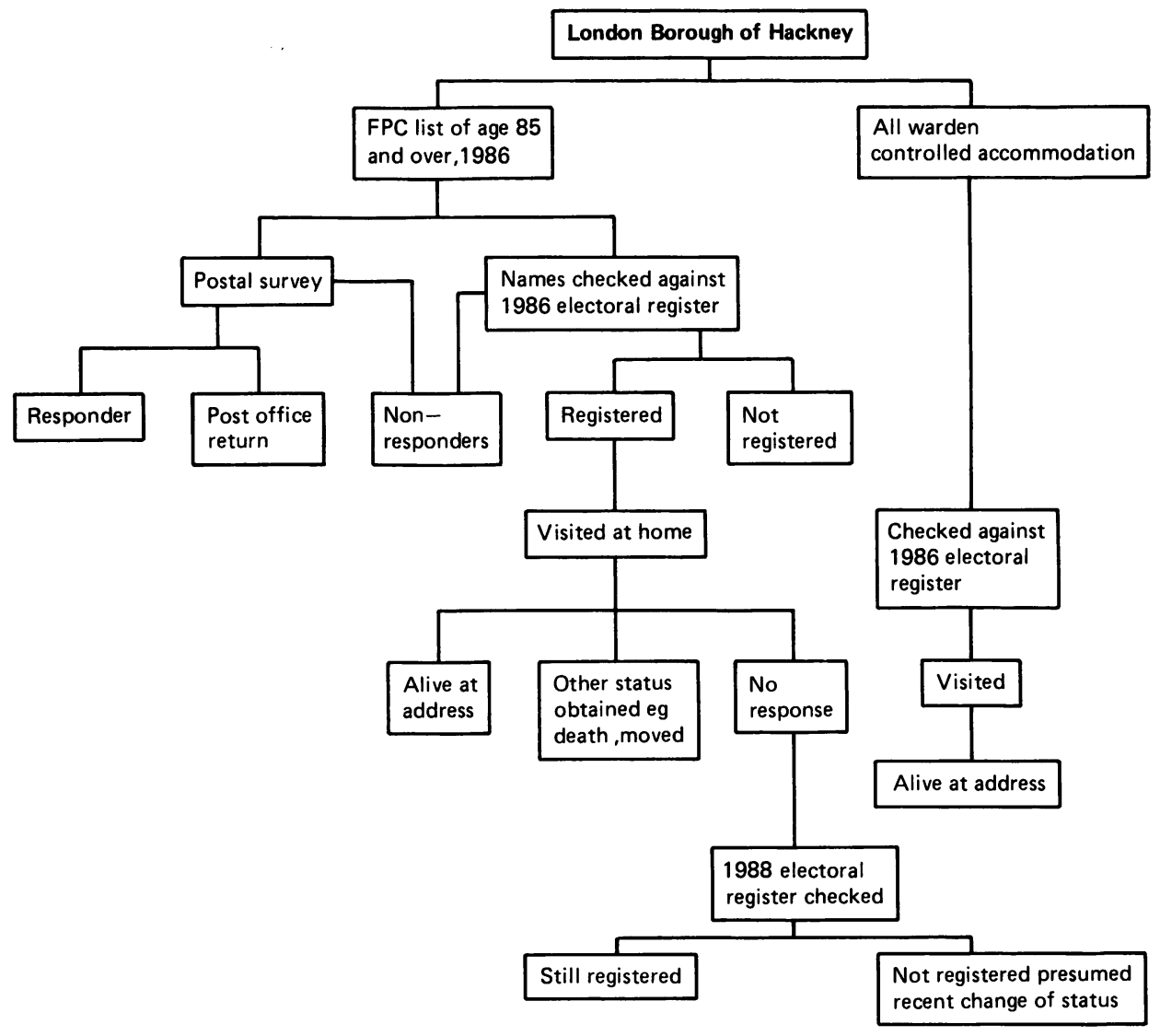

Fig 1 Flow diagram showing methods used in data collection. 


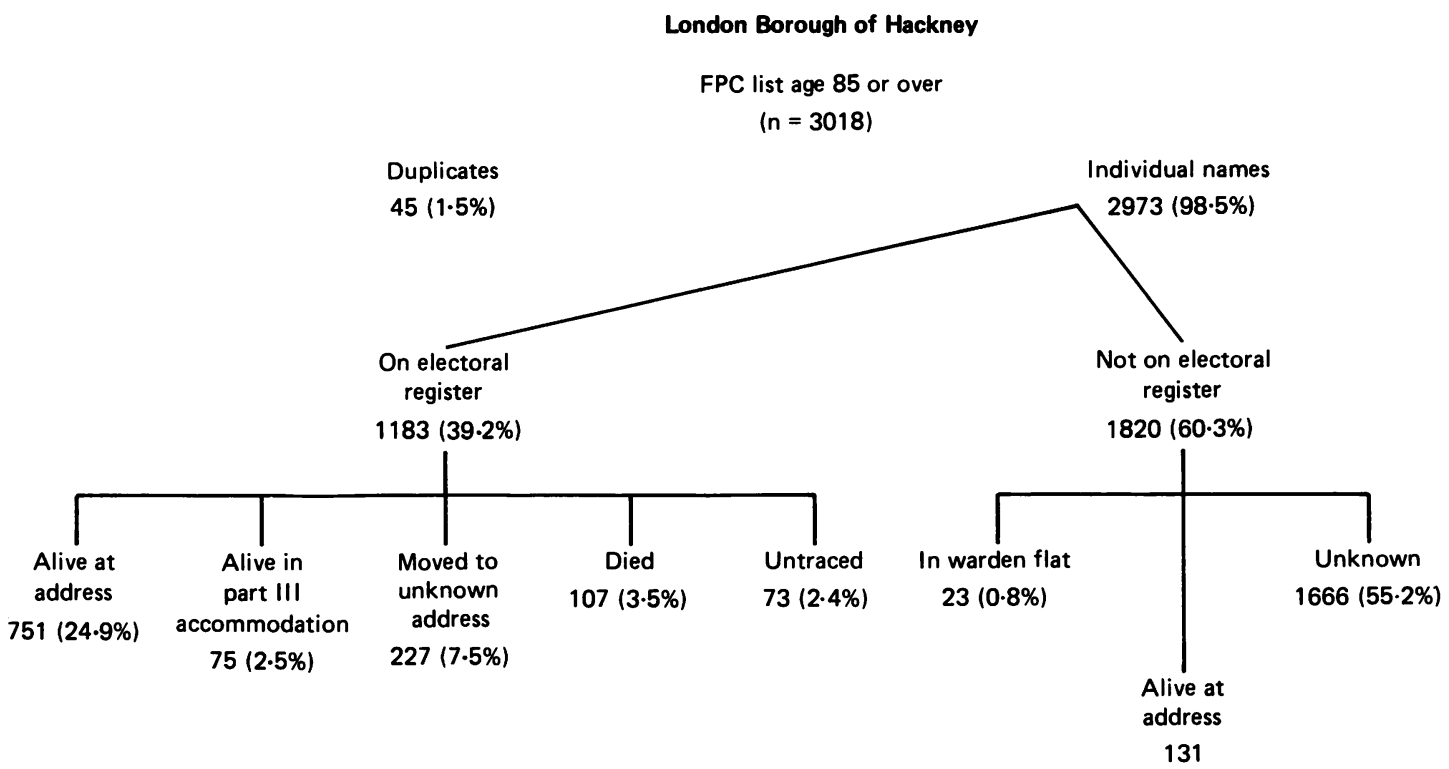

Percentages refer to percent of original FPC list total

Fig 2 Status of 3018 individuals identified on the Hackney Family Practitioner Committee (FPC) list.

between the two registers noted. As a further check the residents of warden controlled sheltered housing units for the elderly in the borough were surveyed, and their presence or absence on the electoral register noted.

As a validation check to determine the likelihood of Family Practitioner Committee registered individuals not on the electoral register yet living at their stated address, a sample of two thirds of the Family Practitioner Committee population not on the electoral roll was surveyed by post.

\section{Results}

The 3018 individuals on the Family Practitioner Committee list included 45 duplicate names, leaving a total of 2973. The status of these latter individuals, after all inquiries, is shown in fig 2.

In total, only $905(30.0 \%)$ of the original Family Practitioner Committee list population were alive at a known residential address (excluding the $2.5 \%$ in residential care) within the borough, of whom 751 $(83 \%)$ were on the electoral register. If this 751 is expressed as a percentage of the proportion found on the electoral register then $63 \%$ of those on the Family Practitioner Committee list and the electoral register were traced and found to be alive at an address within the borough. The majority of the original Family Practitioner Committee list (1966 or 65\%) were untraceable at a current address within the borough, and given their age, most were presumed to have died or moved into sheltered or other accommodation some years previously. Of these untraceables only 300 $(15 \cdot 3 \%)$ were still on the current electoral register. The number of noted deaths, 107 (3.5\%), was surprisingly low given the two year duration of study. Data collected by the Office of Population Censuses and Surveys for the London Borough of Hackney for the year 1986 suggest 333 deaths per year among people aged 85 and over, and thus perhaps as many as $\mathbf{5 0 0}$ $(25 \%)$ of the untraceables had died since the compilation of the Family Practitioners Committee lists.

A sample survey of two thirds of the 1820 people listed on the Family Practitioners Committee register but not on the electoral roll suggested that overall 154 $(8 \%)$ were alive and still living at the address listed by the Family Practitioner Committee or had transferred to a warden controlled flat.

\section{Discussion}

There are a number of observations to be made from the results of this study. First, the available Family Practitioner Committee lists were inadequate as a tool for use as a sampling frame for the elderly in an inner city area. The majority of the very elderly on such lists are actually untraceable - the overestimate of population size according to Family Practitioner 
Committee registers can be up to three times the correct figure. Secondly, this coexistence of an individual on both the Family Practitioners Committee list and on the current electoral register indicates that the chances of discovering their current whereabouts is high. Sixty three per cent of those listed on both the Family Practitioners Committee list and the electoral register were traced to a known private address within the borough. Through this method relatively high response rates can be obtained in relation to those eligible to be surveyed, although it may require supplementation with checks on death certification and investigative work with neighbours, local councils, sheltered housing units and even general practitioners to discover the whereabouts and circumstances of those who have moved or died. While lists from Family Practitioner Committees can be checked against the electoral roll in order to delete names of people no longer registered who may have died or moved, it is not possible to reverse this procedure and check those aged $85+$ on the electoral register against the Family Practitioner Committee list, because age is not given on the electoral register. A further source of information about individuals who might have died is the NHS Central Register at Southport. However, tracing people through this source is expensive, there is frequently a long delay, and the Office of Population Censuses and Surveys, which holds responsibility for the register, usually requires scientific justification for tracing.

Lists obtained from general practitioners themselves are more accurate than lists obtained from the Family Practitioner Committee because general practitioners do not always immediately inform the committees of patients' deaths or changes of address, and notifications are also subject to administrative delay. ${ }^{7}$ However, not all general practitioners have updated age-sex registers, and it is much easier for researchers to negotiate with one body-the Family Practitioner Committee-for lists of names and addresses, than with all the general practitioners within a health district (who can number as many as 250).

The additional exercise of writing to people recorded on the Family Practitioner Committee list enabled us to check the accuracy of their registers. This allows us to estimate that one in six of available individuals will be missed by the requirement to be included on both data sources.

The use of Family Practitioner Committee lists alone to identify the very elderly in an inner city population is too inaccurate to be of value. The combined use of both Family Practitioner Committee lists and the electoral register yields a more realistic estimate, although one in six of available individuals will be missed by the requirement to be included on both data sources. The Family Practitioner Committee lists would be of far greater value if general practitioners could be encouraged to inform the Committee immediately of any deaths among their patients, and to regularly update patients' addresses and inform the Committee of any changes (eg, receptionists could check their addresses routinely as they consult the practice). Now that Family Practitioner Committees are computerised frequent updating of central records is a realistic task.

We gratefully acknowledge financial assistance from North East Thames Regional Health Authority and City and Hackney Health Authority and Social Services Department.

Address for correspondence and reprints: Dr Ann Bowling, Senior lecturer, Health Services Research Unit, Department of Public Health and Policy, London School of Hygiene and Tropical Medicine, Keppel Street, London WC1E 7HT, UK.

\section{References}

${ }^{1}$ Martin J, Meltzer H, Elliot D. The prevalence of disability in adults. OPCS surveys of disability in Great Britain. Report 1. London: Her Majesty's Stationery Office, 1988.

${ }^{2}$ Cartwright A, Smith C. Identifying a sample of elderly people by a postal screen. Age Ageing 1987; 16: 119-22.

3 Todd J, Butcher B. Electoral registration in 1981. London: Office of Population Censuses and Surveys, 1981.

${ }^{4}$ Cartwright A, Anderson R. General practice revisited. A second study of patients and their doctors. London: Tavistock Publications, 1981.

${ }^{5}$ Salvage AV, Jones DA, Vetter NJ. Awareness of and satisfaction with community services in a random sample of over 75s. Health Trends 1988; 3: 88-92.

${ }^{6}$ Williams ES, Barley NH. Old people not known to the general practitioner: a low risk group. $\mathrm{Br} M e d J$ 1985; 2: 445-8.

${ }^{7}$ Graham H, Livesley B. Changes in the population aged over 75 of an urban general practice: implications for screening. Br Med J 1986; 292: 453-4.

${ }^{8}$ Ebrahim S, Hedley R, Sheldon M. Low levels of ill health among elderly non-consulters in general practice. $\mathrm{Br} \mathrm{Med}$ J 1984; 289: 1273-5.

Accepted for publication June 1989 